\title{
Angle Class I malocclusion with anterior open bite treated with extraction of permanent teeth
}

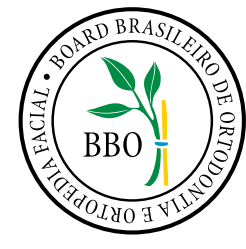

Matheus Melo Pithon ${ }^{1}$

This clinical case reports the orthodontic treatment of a Class I malocclusion with anterior open bite and bimaxillary dentoalveolar protrusion in a 28 -year-old female patient. The treatment of choice was to perform tooth extractions followed by retraction of the anterior teeth, with consequent closure of the anterior open bite and better accommodation of the teeth on their bony bases. This case was presented to the Brazilian Board of Orthodontics and Facial Orthopedics (BBO), representing the Category 2 - i.e., an Angle Class I malocclusion, with anterior open bite, treated with extraction of permanent teeth - , as part of the requisites to become a $\mathrm{BBO}$ diplomate.

Keywords: Open bite. Tooth extraction. Corrective orthodontics.

O presente caso clínico apresenta o tratamento ortodôntico de uma má oclusão de Classe I de Angle com mordida aberta anterior e biprotrusão dentária, em paciente do sexo feminino com 28 anos de idade. $\mathrm{O}$ tratamento de escolha para o caso foi o de extrações dentárias, seguidas por retração dos dentes anteriores, com consequente fechamento da mordida aberta anterior e melhor acomodação dos dentes em suas bases ósseas. Esse caso foi apresentado à Diretoria do Board Brasileiro de Ortodontia e Ortopedia Facial (BBO) como parte dos requisitos para a obtenção do título de Diplomado pelo BBO.

Palavras-chave: Mordida aberta. Extração dentária. Ortodontia corretiva.

\section{HISTORY AND ETIOLOGY}

The patient, a woman aged 28 years and 8 months presented for the initial consultation in a good state of general health, with the chief complaint that her "front teeth did not touch, and they were unable to cut anything". Her dental history contained no significant records, only some previously performed restorations without endodontic involvement, and moderate bone loss in the region of the maxillary and mandibular molars. The patient reported that she had the habit of biting her nails (onicophagy) when she was nervous. In addition, reported that she did not remember when her mandibular right first molar was

${ }^{1}$ Professor, Southwest Bahia University - UESB. Diplomate of Brazilian Board of Orthodontics and Dentofacial Orthopedics, BBO.

* Clinical case, category 2, accepted by the Brazilian Board of Orthodontics and Dentofacial Orthopedics, BBO.

How to cite this article: Pithon MM. Angle Class I malocclusion with anterior open bite treated with extraction of permanent teeth. Dental Press J Orthod. 2013 Mar-Apr;18(2):133-40. extracted (tooth \#46). As regards functional activities, she presented alterations in the tongue position during swallowing movements. She had adequate oral hygiene, despite of a high frequency of caries.

\section{DIAGNOSIS}

Regarding the facial aspect, the patient presented a convex profile (UL-S line $=+4 \mathrm{~mm}, \mathrm{LL}-\mathrm{S}$ line $=+6 \mathrm{~mm}$ ) with passive lip sealing, diminished nasolabial angle, increased lower facial third, lack of space to accommodate teeth \#12 and \#22, and absence of noticeable asymmetries (Fig 1).

\footnotetext{
» The author reports no commercial, proprietary or financial interest in the products or companies described in this article.

» The patient displayed in this article previously approved the use of her facial and intraoral photographs.
}

Contact address: Matheus Melo Pithon Av. Otávio Santos, 395, sala 705 - Recreio CEP: 45.020-750 - Vitória da Conquista / BA - Brazil E-mail: matheuspithon@gmail.com 

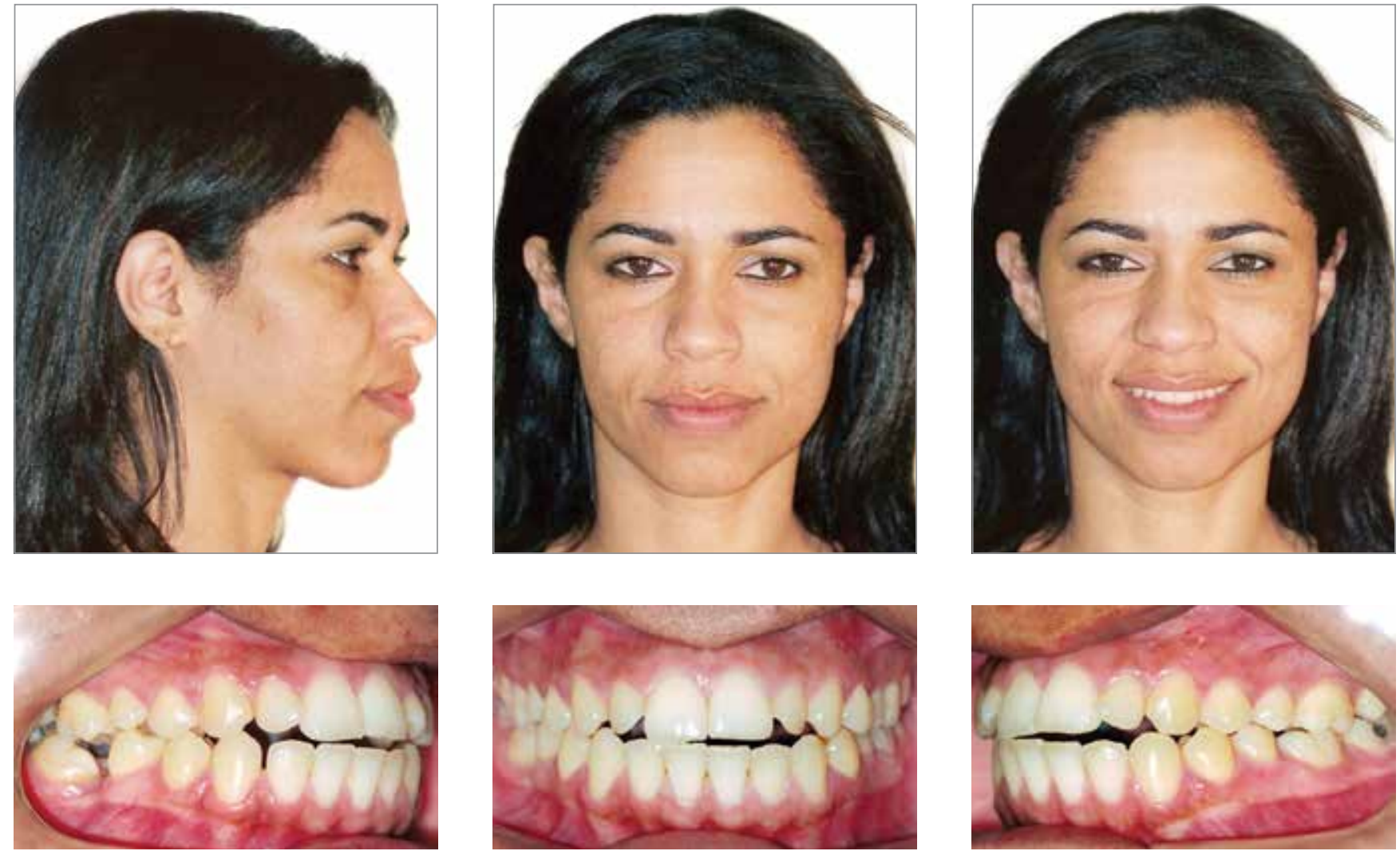

Figure 1 - Facial and intraoral initial photographs.
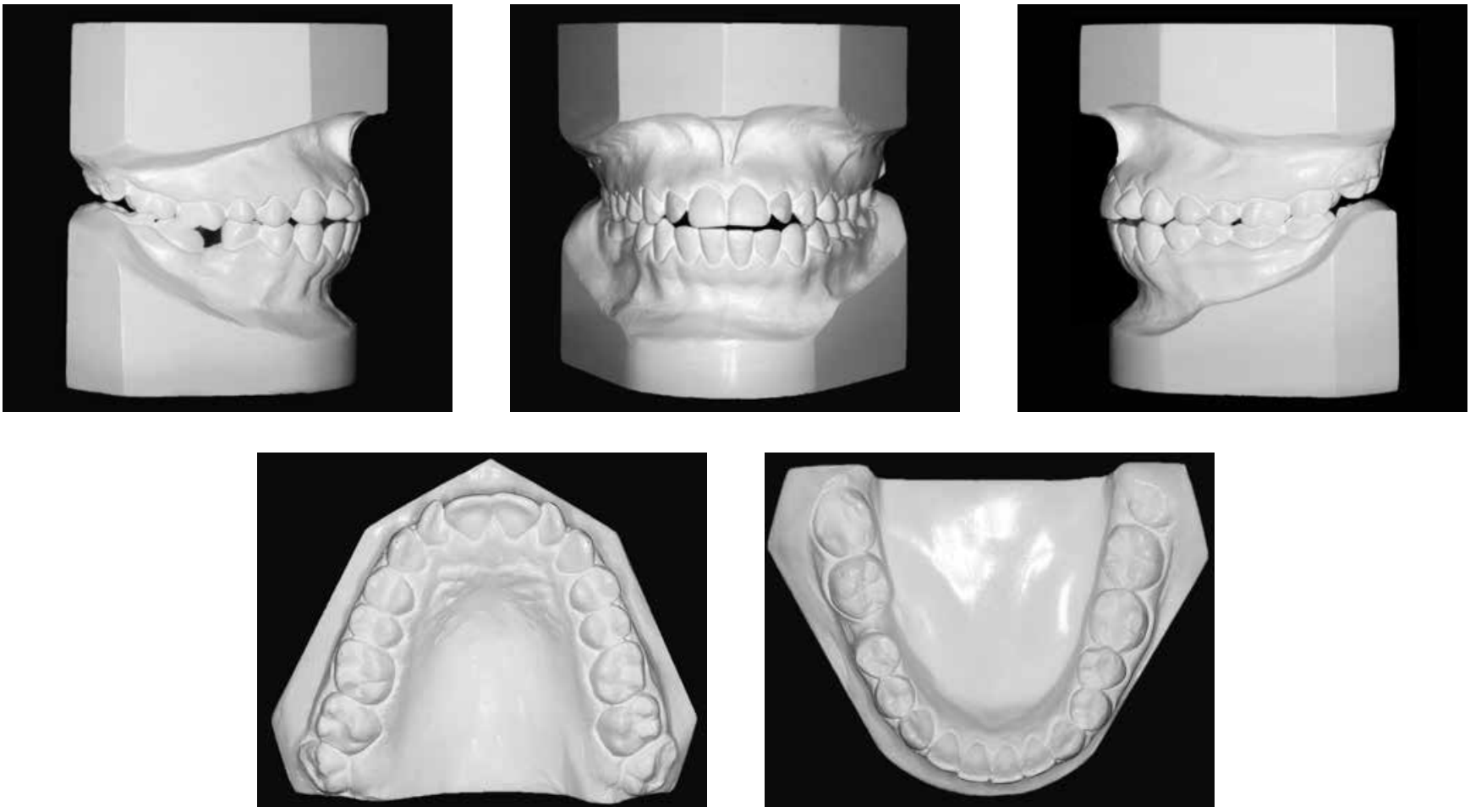

Figure 2 - Initial casts. 
The occlusal analysis revealed an Angle Class I malocclusion; excessive space in mandibular arch, with a $3.6 \mathrm{~mm}$ arch length excess, mandibular tooth size discrepancy with excess of $2.9 \mathrm{~mm}$ in the posterior region and $1.1 \mathrm{~mm}$ in the anterior region; coincident maxillary midline, and mandibular midline with a $0.5 \mathrm{~mm}$ deviation to the right; $0.5 \mathrm{~mm}$ overjet and anterior open bite of $2 \mathrm{~mm}$ in the region of the lateral incisors and left canine, and $1 \mathrm{~mm}$ in the region of the central incisors and mandibular right molars, which were mesially tipped (Figs 1 and 2).

With regard to the asymmetries, in the anteroposterior direction, tooth \#26 was $1 \mathrm{~mm}$ towards the mesial direction in relation to the $\# 16$; and tooth $\# 23,0.5 \mathrm{~mm}$ mesial to the \#13; tooth \#33, $3 \mathrm{~mm}$ mesial to the \#43. In the transverse direction, tooth \#26 was $1 \mathrm{~mm}$ buccal in relation to the \#16; tooth \#23, $0.5 \mathrm{~mm}$ buccal to the \#13; and tooth \#43, $1 \mathrm{~mm}$ buccal to the \#33. Both dental arches presented a parabolic shape with excess of space in the mandibular arch - as a result of the premature extraction of tooth \#46 - and lack of space in the maxillary arch to accommodate teeth \#12 and \#22 (Fig 2).

In the panoramic radiograph, it was verified the inclination of mandibular right molars (teeth \#47 and \#48) in the mesial direction, due to tooth \#46 extraction; moderate bone loss in the maxillary and mandibular molars region; radiopaque images in the premolars and molars crowns, compatible with the image of metal restorations; and presence of all third molars (Fig 3).
The periapical radiographs revealed root resorption in the maxillary incisors, with greater loss in teeth \#21 and \#22. Loss of alveolar bone crest could also be seen in the anterior region (Fig 3).

As regards the skeletal characteristics: There was a skeletal Class II $\left(\mathrm{ANB}=7^{\circ}\right)$, with the maxilla protruded in relation to the cranial base, and the mandible well positioned $\left(\mathrm{SNA}=90^{\circ}\right.$ and $\left.\mathrm{SNB}=83^{\circ}\right)$; a balanced growth pattern, with a tendency towards vertical facial growth $\left(\mathrm{SN}-\mathrm{GoGn}=39^{\circ}\right)($ Fig 4 and Table 1$)$.

The cephalometric analysis (Fig 4 and Table 1) also informed about the projection and buccal inclination of the maxillary and mandibular incisors $\left(1 . \mathrm{NA}=25^{\circ}\right.$, $1-\mathrm{NA}=6 \mathrm{~mm}, 1 . \mathrm{NB}=49^{\circ}$ and $1-\mathrm{NB}=15 \mathrm{~mm}$ ).

With regard to the functional aspect, the patient presented no canine guides, and anterior guide with various posterior premature occlusal contacts.

\section{TREATMENT OBJECTIVES}

The treatment goals were: Reduction of the bimaxillary protrusion, with decrease of the nasolabial angle; closure of the anterior open bite; teeth alignment and leveling, achieving good axial inclinations and closure of all spaces; correction of mesiodistal size of the teeth, eliminating the tooth size discrepancy; symmetry of maxillary and mandibular dental arches; in addition to achieving normal overbite and overjet with canines in Class I relationship.

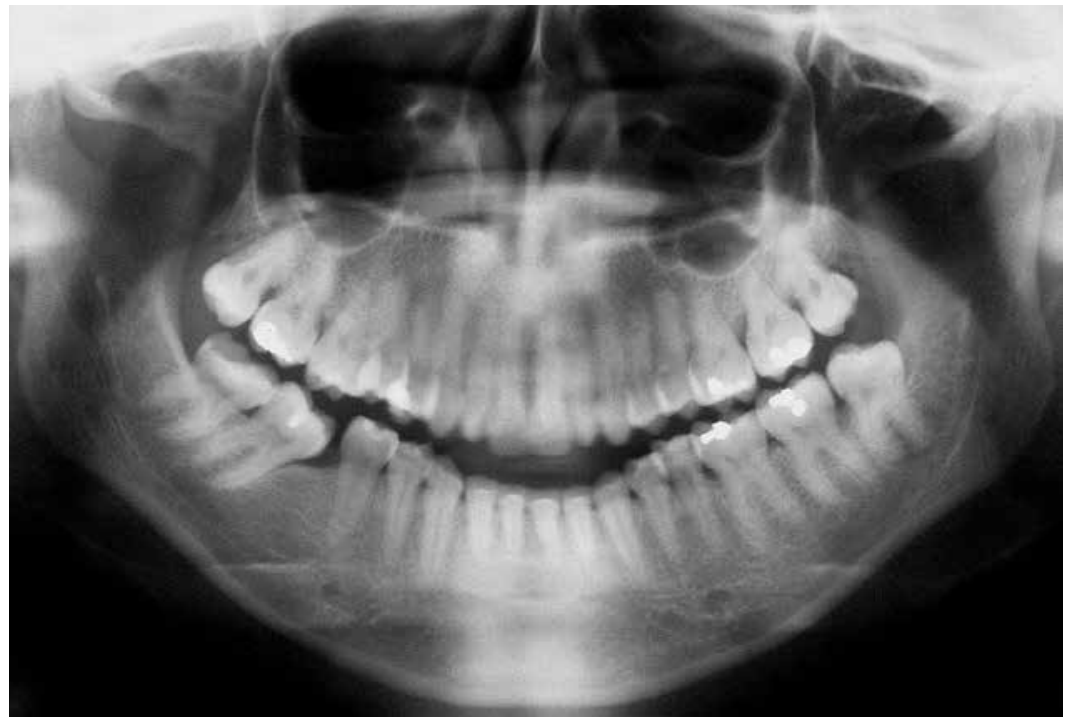

Figure 3 - Initial panoramic and periapical radiographs.

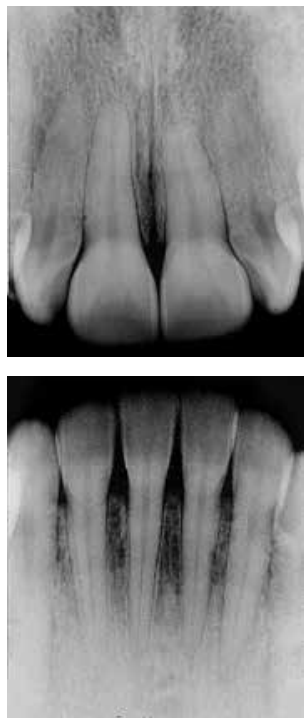



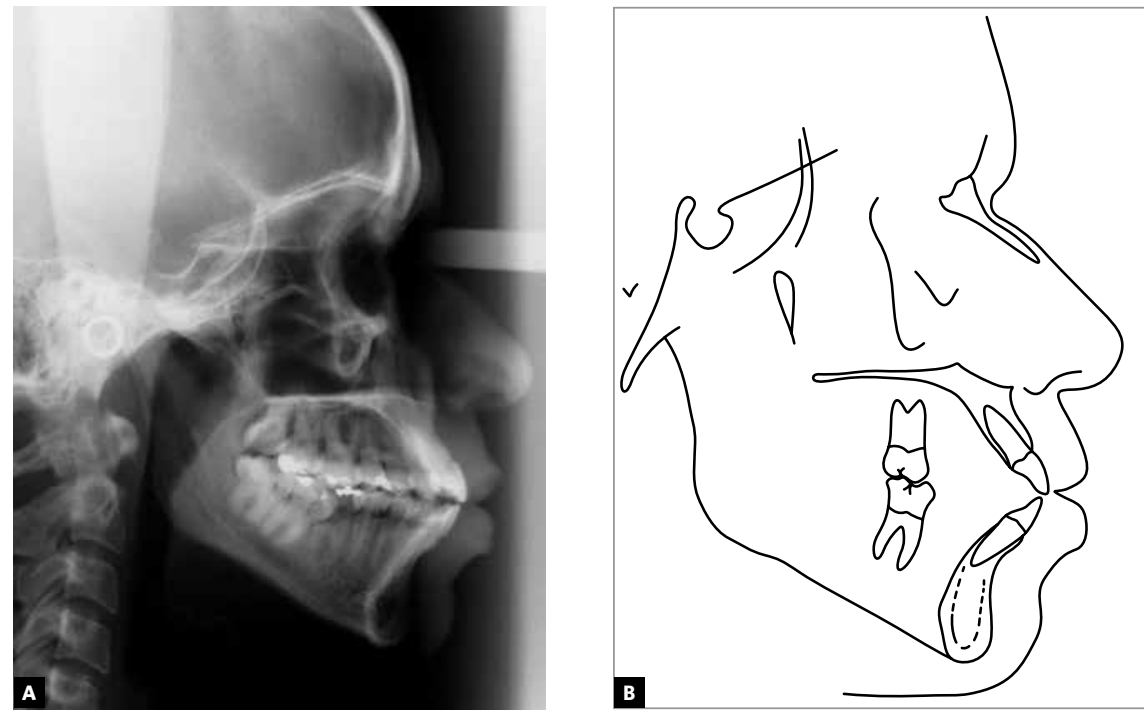

Figure 4 - Initial cephalometric profile radiograph (A) and cephalometric tracing (B)

\section{TREATMENT PLAN}

The proposed treatment plan was the extraction of maxillary first premolars (\#14 and \#24) and one mandibular first premolar, tooth \#34. The extraction of tooth \#44 was not proposed because the patient had suffered early loss of tooth \#46. As anchorage resources, it was installed a mandibular lingual arch and a Nance plate in the maxillary arch (Nance button with increased dimensions of the acrylic part). As an alternative treatment plan, the placement of orthodontic mini-implants was proposed to the patient, instead of using the Nance plate and the lingual arch. Initially, the idea was to partially install the appliance in the maxillary arch, without bonding teeth \#12 and \#22 - which showed lack of space for alignment -; insert the Nance plate and extract teeth $\# 14$ and \#24. After partial retraction of teeth \#13 and $\# 23$ in a 0.020 -in passive archwire, teeth \#12 and \#22 would be included followed by alignment and leveling with 0.012-in, 0.014-in, 0.016-in, 0.018-in and 0.020in archwires. Retraction of canines would be concluded in the 0.020 -in archwire, followed by a $0.019 \times 0.026$-in archwire with teardrop loops in the distal region of the lateral incisors, for incisors retraction.

In the mandibular arch, the treatment plan was to mount the orthodontic appliance and then request the extraction of tooth \#34, beginning the alignment and leveling with 0.012-in, 0.014-in, 0.016-in and 0.020-in archwires. After the uprighting of tooth \#47, a lingual arch supported on teeth \#47 and \#36 would be placed, as an anchorage resource. With the 0.020-in archwire in place, retraction of teeth \#33 and \#45 would be performed, followed by the retraction of teeth \#44 and \#43. After the mandibular canines have been retracted, a $0.019 \times 0.026$-in archwire with teardrop loop in the distal region of the lower lateral incisors would be installed for the retraction of the mandibular anterior teeth.

After the retraction of the maxillary and mandibular anterior teeth, intercuspation elastics would be used. When the treatment has been concluded with the correction of malocclusion, the orthodontic appliance would be removed, followed by the insertion of a wraparound retainer in the maxillary dental arch and a bonded lingual retainer in the mandibular arch.

\section{TREATMENT PROGRESS}

To treat this malocclusion an Edgewise standard (0.022 $\mathrm{x} 0.028$-in) fixed appliance was used. Initially, it was performed the banding of teeth \#16, \#17, \#26, \#27, \#36, \#37, $\# 47$ and \#48; placement of single brackets on teeth \#16, $\# 26$, \#36 and \#47, and tubes on teeth \#17, \#27, \#37 and \#48. In the same session a transfer impression was performed for confection of the maxillary Nance plate supported on teeth $\# 16$ and \#26. Then brackets were bonded on the other teeth, with the exception of \#14, \#24, \#34, \#12 and \#22. Extraction of teeth \#14, \#24 and \#34 was requested.

Treatment in the upper arch started with a 0.020 -in passive archwire, and initiation of partial retraction of teeth \#13 and \#23 with chain elastics. During this stage, the posterior teeth were kept tied together, to increase posterior anchorage. After obtaining sufficient space to accommodate teeth \#12 and \#22, brackets were bonded on them, and started the 
alignment and leveling with 0.012-in, 0.014-in, 0.016-in, 0.018 -in and 0.020 -in coordinated and symmetrical archwires with first and second order bends. With the 0.020-in archwire the retraction of teeth \#13 and \#23 was resumed. Then a $0.019 \times 0.026$-in archwire with teardrop loops was placed in the distal region of the lateral incisors. During retraction, the anterior teeth were kept tied together to prevent the opening of spaces. An accentuated curve of Spee was incorporated into the archwire to control the overbite. After the conclusion of this stage, the Nance plate was removed and a $0.019 \times 0.026$-in stainless steel archwire with an ideal shape and torque was fabricated, and coordinated for conclusion of the treatment.

In the mandibular arch, treatment began with the fabrication of 0.012-in, 0.014-in, 0.016-in and 0.020-in continuous archwires with first and second order bends for alignment and leveling. After uprighting of tooth \#47, a transfer impression was performed for fabrication of the lingual arch supported on teeth \#36 and \#47. Then, retraction of teeth \#33 and \#45 began with chain elastics, with the posterior and anterior teeth tied together to form two blocks, a posterior and a anterior. For retraction of anterior teeth a $0.019 \times 0.026$-in archwire with teardrop loops was placed in the distal region of the lateral incisors. During retraction, the anterior teeth were tied together to prevent the opening of spaces. A reverse curve of Spee was incorporated into the archwire to control the overbite. After retraction, the lingual arch was removed and a $0.019 \times 0.026$-in steel archwire was fabricated with an ideal shape and torque,
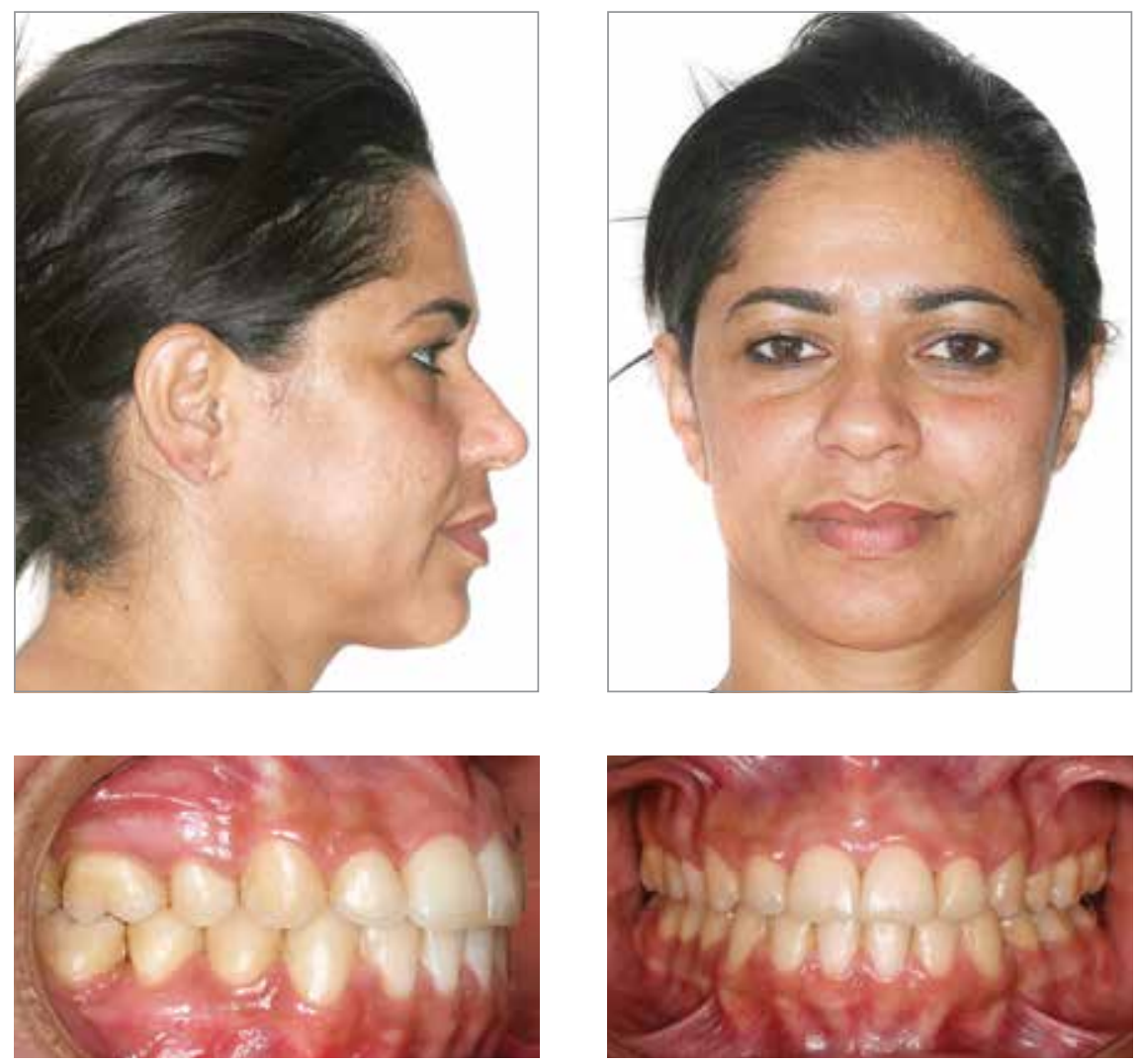
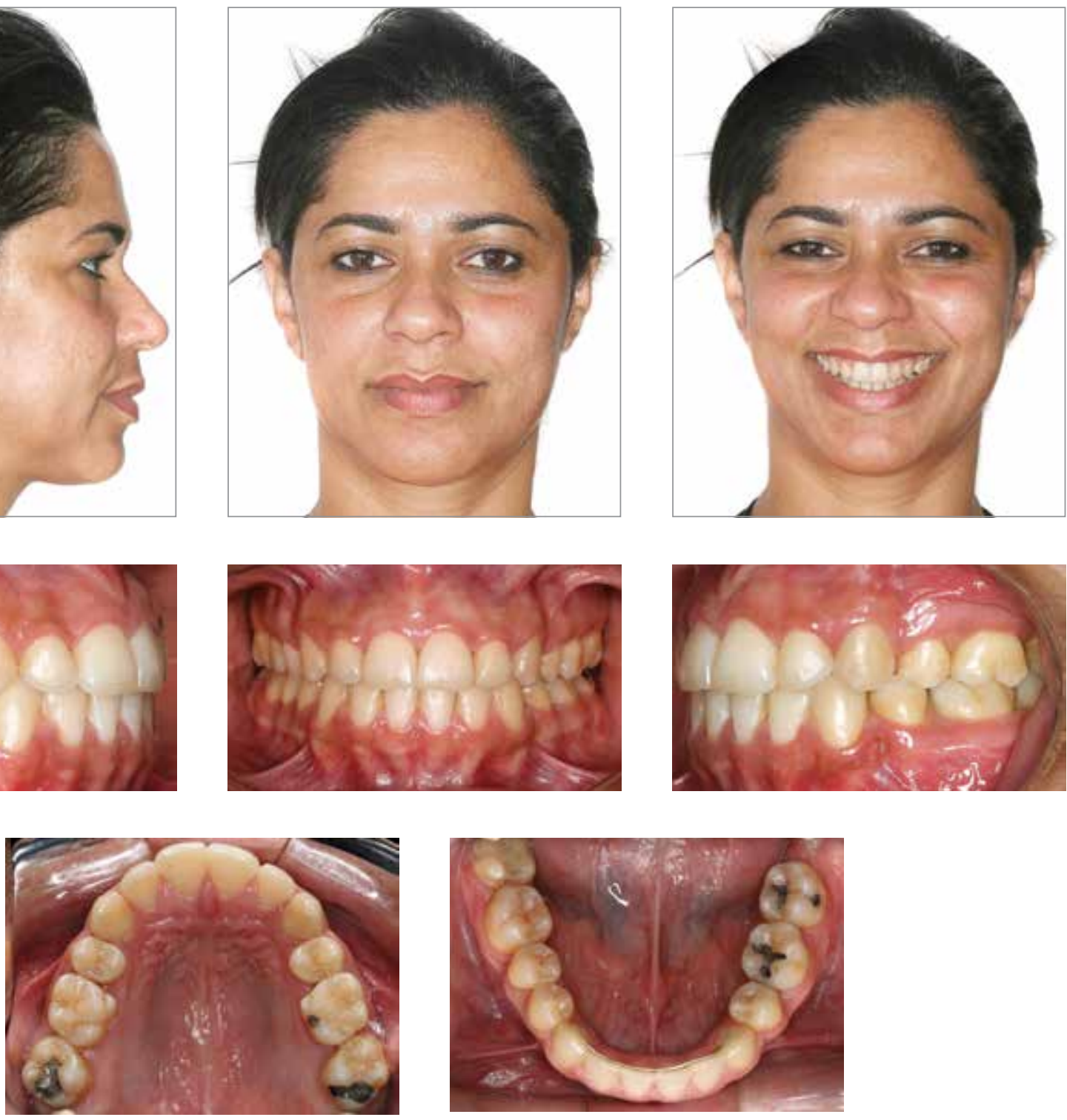

Figure 5 - Facial and intraoral final photographs.

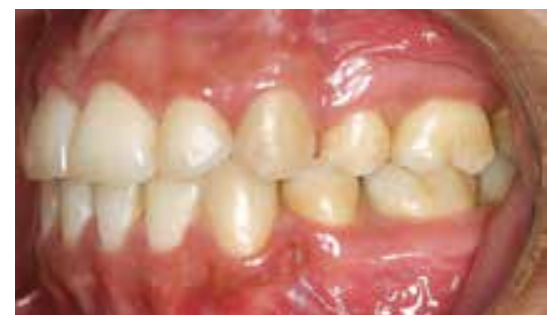


and coordinated for conclusion of the treatment. Intermaxillary elastics for posterior (1/8-in heavy) and anterior (5/16-in medium) intercuspation were used.

After removal of the orthodontic appliance, a wraparound retainer was placed in the maxillary arch and a bonded lingual retainer in the mandibular arch.

\section{RESULTS OBTAINED}

When evaluating the patient's face and her occlusion on the post-orthodontic treatment records, one may verify that all the treatment goals proposed were attained (Figs 5 to 9). With regard to the facial aspect there was improvement in the facial profile, with correction of bimaxillary protrusion, maintenance of passive lip sealing, increase in the nasolabial angle, in addition to obtaining a good smile line with better dental inclinations and good disposition of the teeth in the dental arches (Fig 5).

Skeletally, there was an improvement in the maxillomandibular relationship with a reduction of $1^{\circ}$ in ANB angle, due to the better position of the teeth on their bony bases. The vertical growth pattern remained unaltered, without worsening in the vertical component of the patient's face (Fig 8).

As regards the dental aspect, there was correction of the canine relationship on the right side, which pre- sented in Class II; maintenance of the molar relationship on the left side in Class I; achievement of a Class II molar relationship on the right side; and retraction with discrete extrusion of the maxillary incisors. Maxillary and mandibular molars underwent discrete mesial tipping and did not extrude; the mandibular incisors were retracted and intruded. There was correction of crowding in the maxillary arch and closure of spaces in the mandibular arch; space was obtained in the arch to accommodate teeth \#12 and \#22; uprighting of the mandibular premolars and molars, and readjustment of the mesiodistal diameter of the mandibular anterior and posterior teeth, eliminating the tooth size discrepancy. These changes promoted correction of the contact points and the overjet; also closure of anterior open bite, obtaining a correct overbite; in addition to coordinated and symmetrical dental arches, and midlines coincident with the facial midline (Figs 5 and 6).

With regard to the functional aspect, simultaneous bilateral contacts in harmony with the centric relationship and disocclusion of the posterior teeth by the anterior teeth in mandibular excursive movements were obtained.

With respect to the roots situation, a considerable worsening of root resorption occurred, without compromising the stability of the teeth (Fig 7).
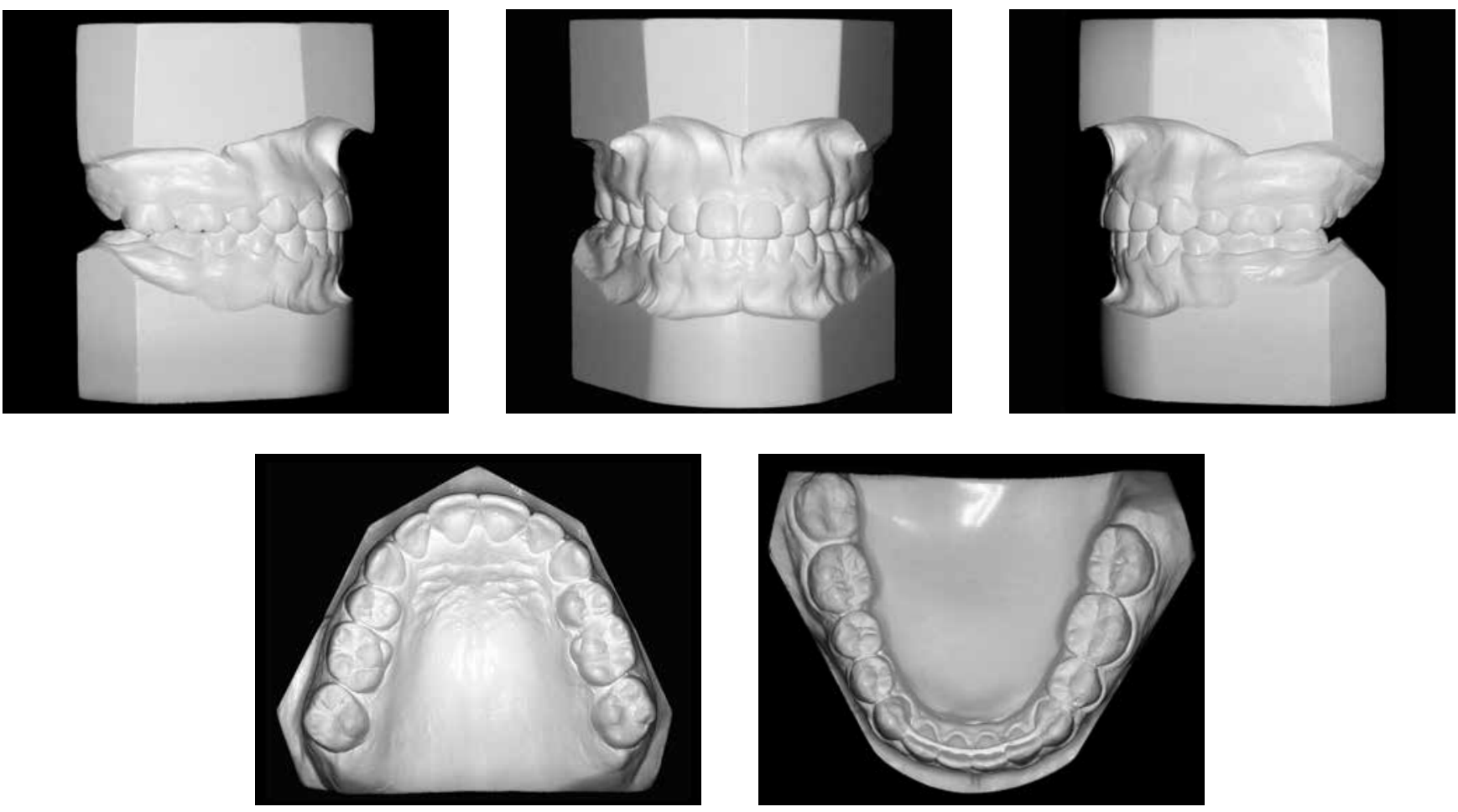

Figure 6 - Final casts 

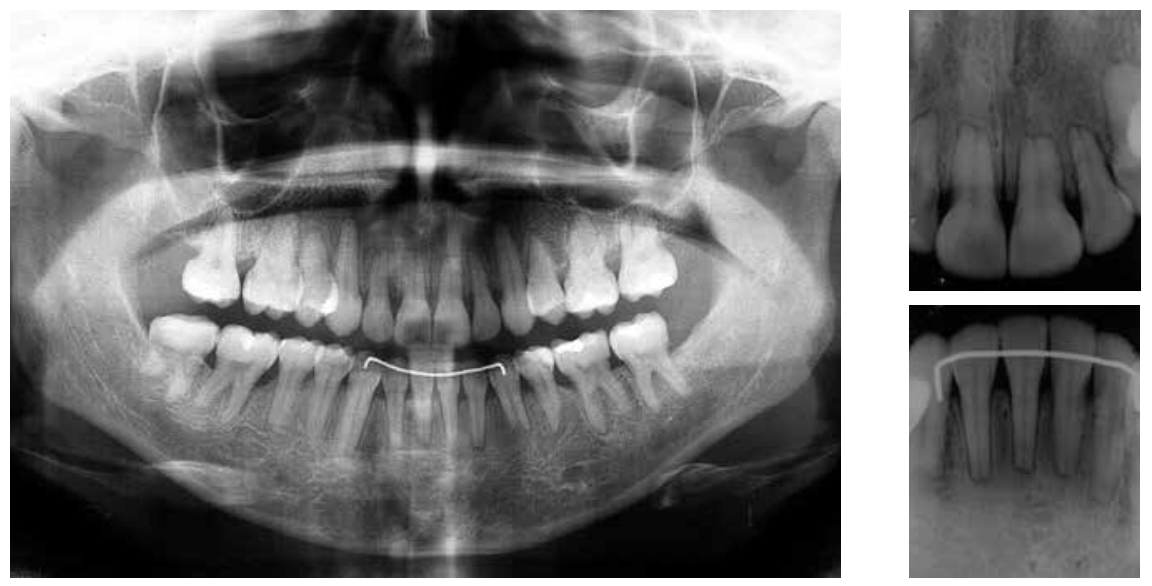

Figure 7 - Panoramic and periapical final radiographs.
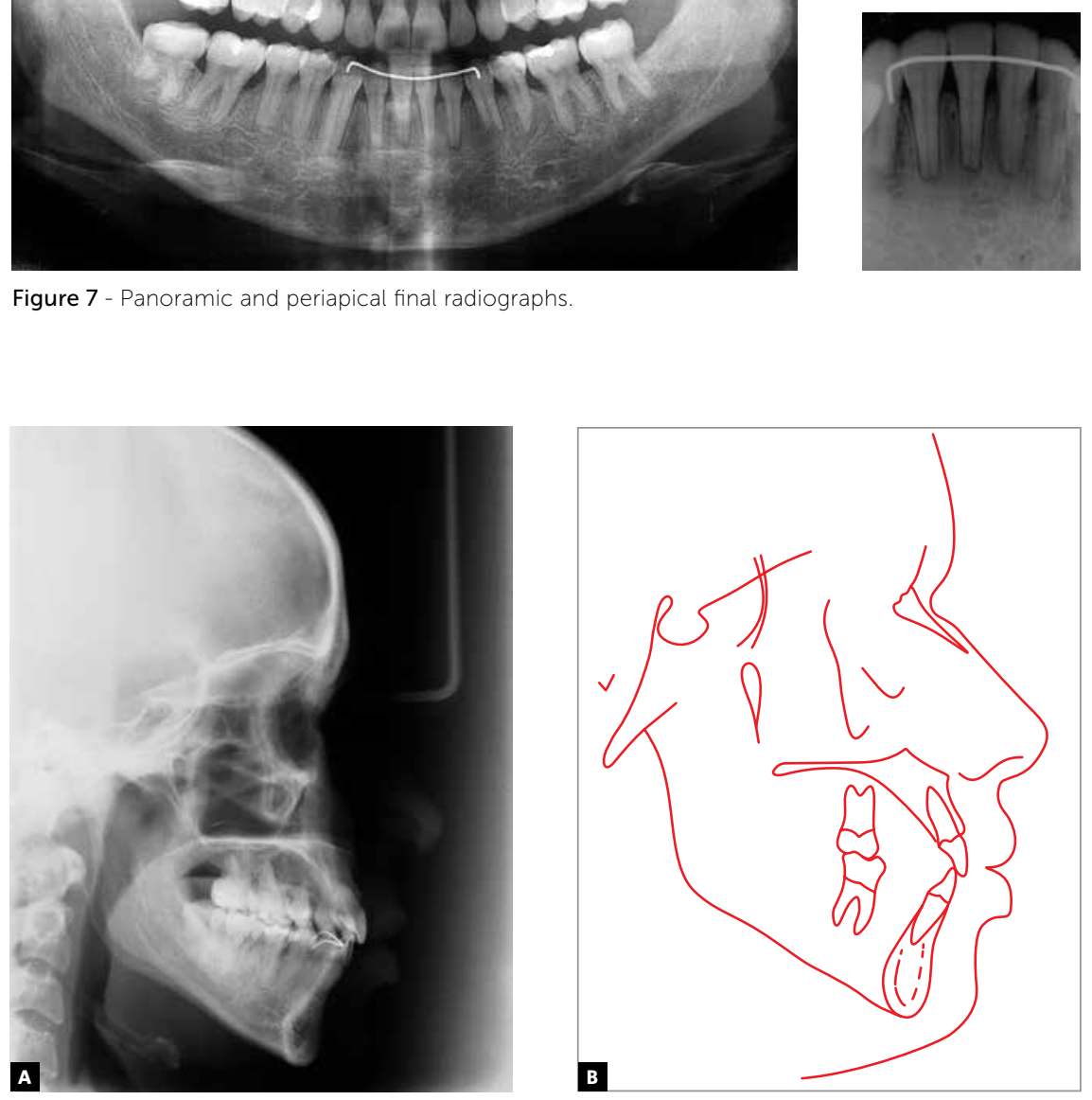

Figure 8 - Final cephalometric profile radiograph (A) and cephalometric tracing (B)
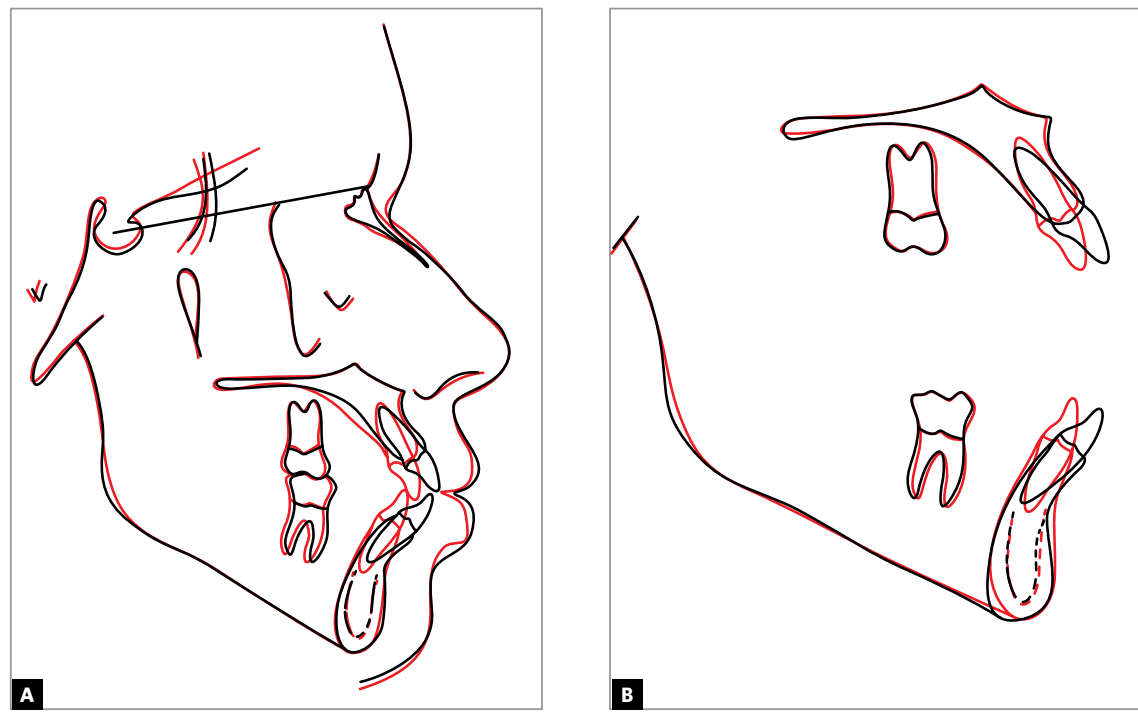

Figure 9 - Total (A) and partial (B) superimpositions of initial (black) and final (red) cephalometric tracings 
Table 1 - Summary of cephalometric measures.

\begin{tabular}{|c|c|c|c|c|c|c|}
\hline & $\mathrm{ME}$ & & Normal & A & B & Diff. A/B \\
\hline \multirow{8}{*}{ Skeletal pattern } & SNA & (Steiner) & $82^{\circ}$ & $90^{\circ}$ & $88^{\circ}$ & 2 \\
\hline & SNB & (Steiner) & $80^{\circ}$ & $83^{\circ}$ & $82^{\circ}$ & 1 \\
\hline & ANB & (Steiner) & $2^{\circ}$ & $7^{\circ}$ & $6^{\circ}$ & 1 \\
\hline & Convexity angle & (Downs) & $0^{\circ}$ & $16^{\circ}$ & $13^{\circ}$ & 3 \\
\hline & $Y$ axis & (Downs) & $59^{\circ}$ & $55^{\circ}$ & $56^{\circ}$ & 1 \\
\hline & Facial angle & (Downs) & $87^{\circ}$ & $95^{\circ}$ & $94^{\circ}$ & 1 \\
\hline & SN-GoGn & (Steiner) & $32^{\circ}$ & $39^{\circ}$ & $39^{\circ}$ & 0 \\
\hline & FMA & (Tweed) & $25^{\circ}$ & $27^{\circ}$ & $28^{\circ}$ & 1 \\
\hline \multirow{7}{*}{ Dental pattern } & IMPA & (Tweed) & $90^{\circ}$ & $108^{\circ}$ & $89^{\circ}$ & 19 \\
\hline & 1.NA (degrees) & (Steiner) & $22^{\circ}$ & $25^{\circ}$ & $15^{\circ}$ & 10 \\
\hline & $\underline{1}-\mathrm{NA}(\mathrm{mm})$ & (Steiner) & $4 \mathrm{~mm}$ & $6 \mathrm{~mm}$ & $3 \mathrm{~mm}$ & 3 \\
\hline & I.NB (degrees) & (Steiner) & $25^{\circ}$ & $49^{\circ}$ & $30^{\circ}$ & 19 \\
\hline & I-NB (mm) & (Steiner) & $4 \mathrm{~mm}$ & $15 \mathrm{~mm}$ & $8 \mathrm{~mm}$ & 7 \\
\hline & $\frac{1}{1}$-Interincisal angle & (Downs) & $130^{\circ}$ & $98^{\circ}$ & $128^{\circ}$ & 30 \\
\hline & 1-APo (mm) & (Ricketts) & $1 \mathrm{~mm}$ & $0 \mathrm{~mm}$ & $0 \mathrm{~mm}$ & 0 \\
\hline \multirow{2}{*}{ Profile } & Upper lip - S line & (Steiner) & $0 \mathrm{~mm}$ & $4 \mathrm{~mm}$ & $2.5 \mathrm{~mm}$ & 1.5 \\
\hline & Lower lip - S line & (Steiner) & $0 \mathrm{~mm}$ & $6 \mathrm{~mm}$ & $3.5 \mathrm{~mm}$ & 2.5 \\
\hline
\end{tabular}

\section{FINAL CONSIDERATIONS}

Orthodontic treatments with tooth extraction have been the reason for controversial debates and opinions. ${ }^{1,2}$ The main discussions are with regard to post-treatment stability, the impact of extractions on facial esthetics and the deepening of the profile. ${ }^{2}$

At present, it is known that the most important factor for reaching post-orthodontic treatment stability, both in cases with and without tooth extractions, is the quality of occlusion on treatment conclusion. ${ }^{3}$ Therefore, one should seek an excellent occlusion, with simultaneous bilateral contacts in harmony with the centric relation and immediate disocclusion of the posterior teeth by the anterior teeth in excursive mandibular movements. ${ }^{4}$

There is consensus that the most significant alterations that occur in the facial profile with orthodontic treatment are in the labial region after the extraction of the first premolars, followed by the retraction of the incisors. Nevertheless, various factors must be considered before making the decision to perform extractions.

\section{REFERENCES}

1. Pithon MM. Orthodontic treatment in an elderly patient with extraction of upper premolar. Gerodontology. 2012;29(2):e1146-51.

2. Ruellas ACO, Ruellas RMO, Romano FL, Pithon MM, Santos RL. Extrações dentárias em Ortodontia: avaliação de elementos de diagnóstico. Dental Press J Orthod. 2010;15(3):134-57.
These factors are the facial profile esthetics, size of the nose, position of the mandibular incisors, facial typology, state of the gingival tissues, amount of crowding, treatment biomechanics, predicted facial growth and type of malocclusion. ${ }^{5}$

In this clinical case, the option was taken for treatment with extractions, because the patient presented very projected incisors that interfered in facial esthetics. The results derived from this chosen treatment were shown to be satisfactory, since the incisors became well positioned on their bony bases, and a good relationship between the dental arches was achieved without the occurrence of profile deepening, which would have been a disaster in this patient, due to her direct ancestry from black ethnicity.

Based on the records obtained at the end of orthodontic treatment, it can be verified that all the proposed objectives were attained: Class I relationship was obtained for the canines, in addition to reduction in bimaxillary protrusion, correction of overjet and open bite, and of the individual tooth malposition.

3. Teittinen M, Tuovinen V, Tammela L, Schatzle M, Peltomaki T. Long-term stability of anterior open bite closure corrected by surgical-orthodontic treatment. Eur J Orthod. 2012;34(2):238-43.

4. Oliveira MV, Pithon MM. Attempted traction of impacted and ankylosed maxillary canines. Am J Orthod Dentofacial Orthop 2012;142(1):106-14.

5. Steyn CL, Maritz JS, du Preez RJ, Harris AM. Facial profile changes with various orthodontic premolar extraction sequences during growth. SADJ. 2004:59(4):139-41, 143-5. 